UDC 691.327

Author: CHERNISHOV Evgeny Mihalovich, Acad RAASN, Dr. of Tec., Professor, Director of the Academic Center, Voronezh State Technical University, 20-letiya Ok-tayabrya St., 84, Voronezh, 394006, e-mail: chem@vgasu.vrn.ru;

Author: SLAVCHEVA Galina Stanislavovna, Dr. of Tec. Sci., Chief Researcher of Ice Research Laboratory, School of Engineering, Far Eastern Federal University. Vladivostok. 8 Sukhanova St., Vladivostok, Russia, 690950, e-mail: gslavcheva@yandex.ru;

Author: ARTAMONOVA Olga Vladimirovna, Ph. D. in Chemistry, Assoc. Prof. of Department of Chemistry, Voronezh State Technical University, 20-letiya Oktayabrya St., 84, Voronezh, 394006, e-mail: ol_artam@rambler.ru

\title{
CONTROL OF RHEOLOGICAL AND STRUCTURAL PROPERTIES CEMENT STONE AT THE NANOMODIFICATION
}

\section{Extended Abstract:}

The efficiency of the use of nanotechnology solutions specially grown nanoparticles to regulate the rheological properties, the kinetics of setting and hardening of the modified cement stone.

Modification of the cement stone structure was carried out using the synthesized authors complex nanomodifier (CNA) on the basis of $\mathrm{SiO}_{2}$ nanopar-ticles and superplasticizer GLENIUM ${ }^{\circledR}$ ACE 30 based on polycarboxylate. The originality of the author's approach is the method of synthesis and the method of administration of complex nanomodifier based on $\mathrm{SiO}_{2}$. CNA was prepared in an aqueous medium, which is then used both as a cement mixing water system.

It was found that the use of the synthesized CNA reduces the viscosity of the cement paste is 1.5 times, extends the setting time, provides in the first days of hardening strength increase by 4.5 times in comparison with the unmodified system. It is important that the optimum dosage of CNA is only $0.01 \%$ by weight of cement. Achieved effects are associated with the manifestation of the role of structure particles embryos substrate for crystallization centers tumors zoning.

Keywords: system hardening cement, complex nano-based additives of $\mathrm{SiO}_{2}$, nanoefficiency by modifying the rheology, setting time, strength. 
MACHINE-READABLE INFORMATION ON CC-LICENSES (HTML-CODE) IN METADATA OF THE PAPER

$<$ a rel="license" href="http://creativecommons.org/licenses/by/4.0/">>img alt="Creative Commons License" style="borderwidth:0" src="https://i.creativecommons.org/l/by/4.0/88x31.png" $/></ \mathrm{a}><$ br $/><$ span xmlns:dct="http://purl.org/ $\mathrm{dc} /$ terms/" href="http://purl.org/dc/dcmitype/Text" property="dct:title" rel="dct:type" $>$ Control of rheological and structural properties cement stone at the nanomodification $</$ span $>$ by $<$ a xmlns:cc="http://creativecommons.org/ns\#" href="Nanotehnologii vstroitel'stve = Nanotechnologies in Construction. 2016, Vol. 8, no. 6, pp. 87-101. DOI: dx.doi. org/10.15828/2075-8545-2016-8-6-87-101. " property="cc:attributionName" rel="cc:attributionURL" $>$ Chernishov E.M., Slavcheva G.S., Artamonova O.V. </a > is licensed under a <a rel="license" href="http://creativecommons.org/licenses/ by $/ 4.0 / ">$ Creative Commons Attribution 4.0 International License $</ \mathrm{a}>$. $<$ br $/>$ Based on a work at $<$ a xmlns:dct="http:// purl.org/dc/terms/" href=" http://nanobuild.ru/en_EN/nanobuild-6-2016/" rel="dct:source" > http://nanobuild.ru/ en_EN/nanobuild-6-2016/</a $>$. $<$ br $/>$ Permissions beyond the scope of this license may be available at $<$ a xmlns:cc="http: $/ /$ creativecommons.org/ns\#" href="ol_artam@rambler.ru" rel="cc:morePermissions">ol_artam@rambler.ru</a> .

\section{References:}

1. Chernyshov E.M., Artamonova O.V., Korotkikh D.N. etc. Primenenie na-nohimii v tehnologii tverdofaznyh stroitel'nyh materialov: nauchno-inzhenernaja problema, napravlenie i primery realizacii [The use of solid-state technology Nanochemistry in building materials: scientific and engineering challenge, direction and implementation examples]. Stroitel'nye ma-terialy [Building materials]. 2008, № 2, pp. 32-36. (In Russian).

2. Korotkikh D.N., Artamonova O.V., Chernyshov E.M. O trebovanijah k na-nomodificirujushhim dobavkam dlja vysokoprochnyh cementnyh betonov [On requirements to nanomodifying additives for high-strength cement concrete]. Nanotechnologies in construction: A Scientific Internet-Journal. 2009, Vol. 1, № 2, pp.42-49. Available at http://nanobuild.ru/ru_RU/journal/Nanobuild_2_2009_ RUS.pdf (In Russian).

3. $\quad W u$ M., Johannesson B., Geiker M. A review: Self-healing in cementitious materials and engineered cementitious composite as a self-healing material. Con-struction and Building Materials. 2012, № 28, pp. 571-583.

4. Singh L.P., Agarwal S.K., Bhattacharyya S.K. Preparation of silica nanoparticles and its beneficial role in cementitious materials. Nanomaterials, nanotechnology. 2011, Vol. 1, № 1, p. 44-51.

5. Raki L., Beaudoin J., Alizadeh R., Makar J. \& Sato T. Cement and Concrete Nanoscience and Nanotechnology. Materials. 2010, № 3, pp. 918-942.

6. Korotkikh D.N., Sergutkina O.R., Artamonova O.V., Chernyshov E.M. Zol'-gel' sintez nanorazmernyh chastic $\mathrm{SiO}_{2}$ dlja modificirovanija struktury cementnogo kamnja [Sol-gel synthesis of $\mathrm{SiO}_{2}$ nanosized particles for cement stone structure modifying]. Nanotechnologies in construction: A Scientific Internet-Journal. 2010, 
V. 2, № 1, pp. 9-118. Available at: http://nanobuild.ru/ru_RU/journal/Nanobuild_1_2010_RUS.pdf.

7. Bazhenov Y.M. Ispol'zovanie nanosistem $\mathrm{v}$ stroitel'nom materialo-vedenii Ispol'zovanie nanosistem v stroitel'nom materialo-vedenii [Using nanosystems in building materials]. Vestnik MGSU. 2009, № 3, pp. 10-13. (In Russian).

8. Koizumi K., Umemura Y., Tsuyuki N. Effects of chemical admixtures on the silicate structure of hydrated portland cement. Proceedings of the $12^{\text {th }}$ International Congress on the Chemistry of Cement. Montreal, 2007, pp. 64-71.

9. Lothenbach B., Winnefeld F., Figi R. The influence of superplasticizers on the hydration of Portland cement. Proceedings of the 12th International Congress on the Chemistry of Cement. Montreal, 2007, pp. 211-233.

10. Plank J., Bassioni G., Dai Z., Keller H., Sachsenhauser B., Zouaoui N. Neues zur wechselwirkung zwischen zementen und polycarboxylat-fliefimitteln. Proceedings der 16 Internationalen Baustofftagung. Weimar, 2006, Band 1, pp. 579-598.

11. Quercia G., Hüsken G., Brouwers H.J.H. Water demand of amorphous nano silica and its impact on the workability of cement paste. Cement and Concrete Research. 2012, № 42, pp. 344-357.

12. Artamonova O.V., Sergutkina O.R., Ostankova I.V., Shvedova M.A. Sintez nanodispersnogo modifikatora na osnove $\mathrm{SiO} 2$ dlja cementnyh kompozitov [Synthesis of nanosized $\mathrm{SiO}_{2}$ based modifier for cement composites]. Kondensirovannye sredy i mezhfaznye granicy [Condensed substance and phase boundary]. 2014, Vol. 16, № 1, pp. 152-162. (In Russian).

13. Artamonova O.V., Kukina O.B., Solokhin M.A. Issledovanie struktury i svojstv cementnogo kamnja, modificirovannogo kompleksnoj nanodobavkoj [Investigation of the structure and properties of cement paste, modified complex nanoadditive]. Deformacija i razrushenie materialov [Deformation and fracture of materials]. 2014, № 11, pp. 18-22. (In Russian).

14. Chernyshov E.M., Artamonova O.V., Slavcheva G.S. Concepts and technology base nanomodification of structures of building composites. Part 3: effective nanomodification of systems and structures of cement hardening cement stone (criteria and conditions). Stroitel'nye materially [Building materials]. 2015, № 10, pp. 54-63. (In Russian).

15. Chernyshov E.M., Slavcheva G.S., Artamonova O.V. K konceptual'nym modeljam upravlenija soprotivleniem razrusheniju nanomodificirovannyh struktur konglomeratnyh stroitel'nyh kompozitov [About resistance control conceptual model of fracture nanomodified structures of conglomerate building composites]. News KGASU. 2014, № 3 (29), pp. 156-161. (In Russian). 
16. Batrakov V.G. Modified concrete. Theory and practice. Moscow, Stroyizdat, 1998, 768 p. (In Russian).

17. Goddard W.A., Brenner D.W., Lyshewski S.E., Iafrate G.J. Handbook of nanoscience, engineering, and technology. Boka Raton: CRC Hress, 2003, 800 p.

18. Pascenco A.A. Theory of cement. Kiev, Budivelnik, 1991, 168 p. (In Russian).

19. Makridin N.I., Korolev E.V., Maksimova I.N. Strukturoobrazovanie i konstrukcionnaja prochnost' cementnyh kompozitov: monografija [Pattern formation and the structural strength of cement composites: a monograph]. Moscow, MSUCE, 2013, 152 p. (In Russian).

20. Stuzman P. Chemistry and structure of hydration products. Cement Research Progress. 1999, № 2, pp. 37-69.

21. Bullard J.W., Jennings H.M., Livingston R.A., et. al. Mechanisms of cement hydration. Cement and Concrete Research. 2011, № 41, pp. 1208-1223.

22. Chernyshov E.M. Nanotechnology research building composites: general judgment, the main directions and results. Nanotechnologies in construction: A Scientific Internet-Journal. 2009, Vol. 1, №1, pp. 45-59. Available at: http://www. nanobuild.ru/magazine/ nb/Nanobuild_1_2009.pdf (In Russian).

Dear Colleagues!

THE REFERENCE TO THIS PAPER HAS THE FOLLOWING CITATION FORMAT:

Chernishov E.M., Slavcheva G.S., Artamonova O.V. Control of rheological and structural properties cement stone at the nanomodification. Nanotehnologii v stroitel'stve $=$ Nanotechnologies in Construction. 2016, Vol. 8, no. 6, pp. 87-101. DOI: dx.doi.org/10.15828/2075-8545-2016-8-6-87-101. (In Russian). 
удК 691.327

Автор: ЧЕРНЫШОВ Евгений Михайлович, академик РААСН, д.т.н., профессор, директор академического центра «Архстройнаука», Воронежский государственный технический университет; ул. 20-летия Октября, 84, Воронеж, 394008, e-mail: chem@vgasu.vrn.ru;

Автор: СЛАВЧЕВА Галина Станиславовна, д.т.н., зав. Научно-исследовательской лаборатории ледовых исследований МHOЦ R\&D центр «Арктика» Инженерной школы, Дальневосточный федеральный университет; ул. Суханова, 8, Владивосток, 690950, e-mail: gslavcheva@yandex.ru; Автор: АРТАМОНОВА Ольга Владимировна, к.х.н., доцент кафедры химии, Воронежский государственный технический университет; ул. 20-летия Октября, 84, Воронеж, 394008, e-mail: ol_artam@rambler.ru

\section{УПРАВЛЕНИЕ РЕОЛОГИЧЕСКИМИ И КОНСТРУКЦИОННЫМИ СВОЙСТВАМИ ЦЕМЕНТНОГО КАМНЯ ПРИ НАНОМОДИФИЦИРОВАНИИ}

\section{АННОТАЦИЯ К СТАТЬЕ (АВТОРСКОЕ РЕЗЮме, РЕФЕРАТ):}

Доказана эффективность нанотехнологического решения применения специально выращенных наноразмерных частиц для регулирования реологических характеристик, кинетики схватывания и твердения модифицированного цементного камня.

Модифицирование структуры цементного камня осуществлялось с использованием синтезированного авторами комплексного наномодификатора (КНД) на основе наночастиц $\mathrm{SiO}_{2}$ и суперпластификатора GLENIUM ${ }^{\circledR} \mathrm{ACE} 30$ на основе поликарбоксилатных эфиров. Оригинальность авторского подхода заключается в методе синтеза и способе введения комплексного наномодификатора на основе $\mathrm{SiO}_{2}$. КНД получали в водной среде, которая одновременно затем используется в качестве воды затворения цементной системы.

Установлено, что применение синтезированных КНД позволяет снизить вязкость цементного теста в 1,5 раза, удлиняет сроки схватывания, обеспечивает в первые сутки твердения повышение прочности в 4,5 раза по сравнению с немодифицированной системой. Оптимальная дозировка КНД составляет 0,01\% от массы цемента. Достигнутые эффекты связываются с проявлением частицами роли зародышей структурообразования, подложки для кристаллизации, центров зонирования новообразований.

Ключевые слова: система твердения цемента, комплексные нанодобавки на основе $\mathrm{SiO}_{2}$, наномодифицирование. 
МАшИНОЧИТАЕМАЯ ИНФОРМАЦИЯ о CC-ЛИЦЕНЗИИ в МЕТАДАННЫХ СТАТЬИ (НTML-КОД):

$<$ a rel="license" href="http://creativecommons.org/licenses/by/4.0/"><img alt="Лицензия Creative Commons" style="borderwidth:0" src="https://i.creativecommons.org/l/by/4.0/88x31.png" / ></a $><$ br $/>$ Произведение "<span xmlns:dct="http:// purl.org/dc/terms/" href="http://purl.org/dc/dcmitype/Text" property="dct:title" rel="dct:type" >Управление реологическими и конструкционными свойствами цементного камня при наномодифицировании $</$ span $>$ » созданное автором по имени $<\mathrm{a}$ xmlns:cc="http://creativecommons.org/ns\#" href="Нанотехнологии в строительстве. - 2016. - Toм 8, № 6. - C. 87-101. -DOI: dx.doi.org/10.15828/2075-8545-2016-8-6-87-101" property="cc:attributionName" rel="cc:attributionURL"> Чернышов Е.M., Славчева Г.С., Артамонова О.В. </a >, публикуется на условиях < a rel="license" href="http://creativecommons.org/licenses/ by/4.0/">лицензии Creative Commons «Attribution» («Атрибуция») 4.0 Всемирная $</ \mathrm{a}>$. $<\mathrm{br} />$ Основано на произведении с $<$ a xmlns:dct="http://purl.org/dc/terms/" href="http://nanobuild.ru/ru_RU/nanobuild-6-2016/" rel="dct:source">http:// nanobuild.ru/ru_RU/nanobuild-6-2016/</a $>$. $<\mathrm{br} />$ Разрешения, выходящие за рамки данной лицензии, могут быть доступны на странице $<$ a xmlns:cc="http://creativecommons.org/ns\#" href="ol_artam@rambler.ru" rel="cc:morePermissions" $>$ ol_ artam@rambler.ru</a>.

\section{Введение}

Возведение сооружений в экстремальных условиях при освоении полярных территорий России невозможно без активного использования высокопрочных бетонов нового поколения с высоким уровнем строительно-технических свойств и возможностей. В арктических условиях возведения сооружений принципиально важно обеспечить получение бетонных смесей высокой подвижности и живучести для транспортировки их на дальние расстояния и оптимизации процесса бетонирования. Одновременно необходимо сокращение сроков твердения для достижения значений марочной прочности бетона в минимальные сроки в условиях преобладания пониженных и отрицательных температур. Именно поэтому исследование условий управления режимами схватывания и твердения высокопрочных бетонов является актуальной научно-инженерной проблемой.

Получение высокопрочных бетонов нового поколения связано с модифицированием структуры их связующего микро- и наночастицами различного состава и морфологии [1-5]. Среди применяемых в технологии цементных систем современных добавок особое место занимают две большие группы - активные минеральные добавки (АМд) и добавки-пластификаторы. Применение микро- и наночастиц, родственных по кристаллохимическому строению минералам цементного клинкера, позволяет получать цементную матрицу с высокой плотностью, способ-

http://nanobuild.ru 
ствует ускорению гидратации клинкерных минералов, приводит к формированию в цементном камне стабильных высокопрочных структур из низкоосновных гидросиликатов кальция [6-8]. Известно, что наиболее распространенными и эффективными АМД являются добавки на основе $\mathrm{SiO}_{2}$, а именно: аморфный микрокремнезем (d $\left.\cong 50 \div 150 \mathrm{м \kappa м}\right)$ и наночастицы $(\mathrm{d}=5-10$ нм). Однако при их введении в цементные композиции повышается их водопотребность. Данная проблема традиционно решается введением суперпластификаторов, позволяющих снизить количество воды затворения на $30-40 \%$ при сохранении реологических свойств цементного теста [9-11].

Согласно современным представлениям, действие суперпластификаторов (СП) включает комплекс физико-химических процессов, разнонаправленно влияющих на процессы гидратации и твердения цемента. Так, в работе [9] отмечается, что пластифицирующий эффект и замедление гидратации цемента в присутствии поликарбоксилатных добавок обусловлены электростатически-стерическим механизмом их действия, а не химическим взаимодействием с ионами $\mathrm{Ca}^{2+}, \mathrm{Na}^{+}, \mathrm{K}^{+}$. В работах $[8$, 10] показывается, что молекулы поликарбоксилатов образуют метастабильные комплексы с ионами $\mathrm{Ca}^{2+}$, что вызывает понижение основности образующихся гидросиликатных фаз, при взаимодействии с $\mathrm{C}_{3} \mathrm{~A}$ встраиваются в структуру формирующихся гидратов с образованием стабильных органоминеральных фаз.

Результаты наших исследований [12-14] позволили установить, что для модифицирования цементного камня наиболее эффективна комплексная добавка, обязательными компонентами которой являются родственные по кристаллохимическому строению неорганические наночастицы $\mathrm{SiO}_{2}$ и эффективный суперпластификатор (преимущественно на основе поликарбоксилатных эфиров). Оригинальность авторского подхода заключается в методе синтеза и способе введения комплексного наномодификатора на основе $\mathrm{SiO}_{2}$. КНД получают в водной среде, которая одновременно затем используется в качестве воды затворения цементной системы. При этом суперпластификатор, вводимый в комплексную добавку в процессе синтеза, выполняет двойную функцию: стабилизирует рост коллоидных агрегатов кремнезема и в дальнейшем решает технологическую проблему равномерного распределения комплексной добавки и регулирования реологических свойств цементной системы при ее приготовлении. 
В ранее проведенных нами исследованиях установлено [14, 15], что введение в цементно-водную систему наномодифицирующих добавок ускоряет гидратацию цемента в 10-30 раз, что объясняется снижением энергии активации процесса в 2-3 раза. Стоит отметить, что в системах с наномодифицирующими добавками к суточной продолжительности твердения при $20^{\circ} \mathrm{C}(293 \mathrm{~K})$ степень гидратации достигает значений не менее $75 \%$.

Исследования, результаты которых представлены в данной публикации, являются частью комплекса работ по изучению условий эффективного наномодифицирования цементных систем. Впервые показано влияние комплексной наномодифицирующей добавки на основе $\mathrm{SiO}_{2}$ на реологические свойства, режимы схватывания и формирование конструкционного потенциала цементного камня в начальные сроки твердения.

\section{Материалы и методы}

В экспериментах исследовался цементный камень контрольного состава (эталон без добавок) и составов, модифицированных КНД, при варьировании ее дозировки 0,$1 ; 0,01 ; 0,001 \%$ от массы цемента. В качестве наномодификатора применялась синтезированная авторами КНД на основе наночастиц $\mathrm{SiO}_{2}$ и суперпластификатора марки GLENIUM ${ }^{\circledR}$ ACE 30 на основе поликарбоксилатных эфиров.

Синтез КНД осуществлялся по оригинальному авторскому зольгель методу [12]. КНД получали методом обратного титрования исходного раствора силиката натрия соляной кислотой. При постоянном перемешивании коллоидные агрегаты $\mathrm{SiO}_{2}$ стабилизировали раствором СП. Оптимальная концентрация суперпластификатора, стабилизирующая рост частиц $\mathrm{SiO}_{2}$ до оптимальных размеров 5-10 нм, составляла 0,2\% . Золь синтезировали при постоянной температуре $25^{\circ} \mathrm{C}$, время синтеза варьировалось от 25 до 40 мин. Количество и размер коллоидных агрегатов, синтезированных золь-гель методом, определяли:

- методом лазерной дифракции (анализатор размера частиц «Анализетте 22 »), позволявшим контролировать форму синтезируемых частиц;

- динамическим светорассеянием (спектрометр Photocor Complex), просвечивающей электронной микроскопией (ПЭМ, Transmission 
Electron Microscope H - 9500 с 75 кB), позволявшими контролировать изменение размера частиц во времени.

Образцы изготавливались из цементного теста с постоянным В/Ц= 0,28. Для изготовления образцов цементного камня применяли портландцемент CEM I 52,5, соответствующий требованиям российского стандарта ГОСТ 31108-2003 (гармонизирован с CEM EN 197-1).

В экспериментах оценивались следующие характеристики цементных систем:

1. Реологические характеристики цементного теста оценивались по показателю его вязкости $\mu$ путем определения сопротивления вязкому трению на ротационном вискозиметре PB-8M [16]. Для каждого состава цементного теста опыт повторялся не менее $4-5$ раз до достижения стабильных результатов.

2. Кинетика схватывания цементного теста исследовалась по результатам измерения пластической прочности на коническом пластометре конструкции МГУ [17]. Определение значений пластической прочности $\boldsymbol{P}_{m}$ производилось через каждые 15 мин после затворения цемента водой до момента достижения значения $\boldsymbol{P}_{m}=1,5 \cdot 10^{-4} \mathrm{MПа,} \mathrm{соот-}$ ветствующего началу схватывания.

3. Влияние КНД на прочность цементного камня оценивалась по результатам определения предела прочности при сжатии образцов размером $5 \times 5 \times 5$ см в возрасте $1,3,28$ сут после твердения в нормальных условиях. Испытания вели на испытательной системе INSTRON Sates 1500HDS. Для обеспечения статистической достоверности результатов физико-механических испытаний количество образцов в сериях составляло от 9 до 12, внутрисерийный коэффициент изменчивости результатов оценки прочности не превышал $7-10 \%$.

\section{Обсуждение результатов}

\section{Влияние КНД на реологические характеристики иелентного теста}

Применение КНД при всех вариантах использованных дозировок при одинаковом В/Ц позволяет снизить вязкость цементного теста в 1,31,5 раза (см. табл.) по сравнению с эталонной немодифицированной системой при одновременном повышении прочности цементного камня. 
Таблица

\section{Реологические и прочностные характеристики цементных систем}

\begin{tabular}{|c|c|c|c|c|}
\hline \multirow{2}{*}{ Система } & \multirow{2}{*}{$\begin{array}{c}\text { Вязкость } \\
\text { цементного } \\
\text { теста, Па:с }\end{array}$} & \multicolumn{3}{|c|}{ Прочность цементного камня, МПа } \\
\hline & & 1 сут & 3 сут & 28 сут \\
\hline Эталон (без добавок) & 7,39 & 6,5 & 20,0 & 48,9 \\
\hline $\begin{array}{l}\text { С добавкой КНД } 0,1 \% \\
\text { от массы цемента }\end{array}$ & 4,44 & 27,8 & 30,3 & 69,0 \\
\hline $\begin{array}{l}\text { С добавкой КНД } 0,01 \% \\
\text { от массы цемента }\end{array}$ & 5,34 & 27,2 & 35,3 & 76,8 \\
\hline $\begin{array}{l}\text { С добавкой КНД } 0,001 \% \\
\text { от массы цемента }\end{array}$ & 5,28 & 28,5 & 34,7 & 68,1 \\
\hline
\end{tabular}

Наибольшее снижение вязкости цементного теста зафиксировано при дозировке модификатора $0,1 \%$ от массы цемента, что закономерно обусловлено большей концентрацией СП в системе. При этом снижение вязкости цементного теста не менее чем в 1,3 раза обеспечивается и при предельно малых дозировках КНД 0,01\% и 0,001\% от массы цемента. На основании полученных результатов можно заключить, что использование данных добавок позволяет эффективно регулировать реологические характеристики цементного теста, что создает условия их применения для получения высокоподвижных бетонных смесей.

\section{Влияние КНД на кинетику схватывания иелентного теста}

Установлено, что при введении синтезированной КНД во всех вариантах использованных дозировок изменяется характер кинетической кривой пластической прочности $\boldsymbol{P}_{m}$ цементных систем (см. рис.). При этом закономерности кинетики схватывания весьма значительно определяются дозировкой КНД.

В системах с дозировками КНД 0,1 и 0,001\% от массы цемента через 30 и 45 мин после затворения фиксируются эффекты резкого возрастания пластической прочности до значений $\boldsymbol{P}_{m}=(1,2-1,3) \cdot 10^{-4} \mathrm{MПа.}$ 


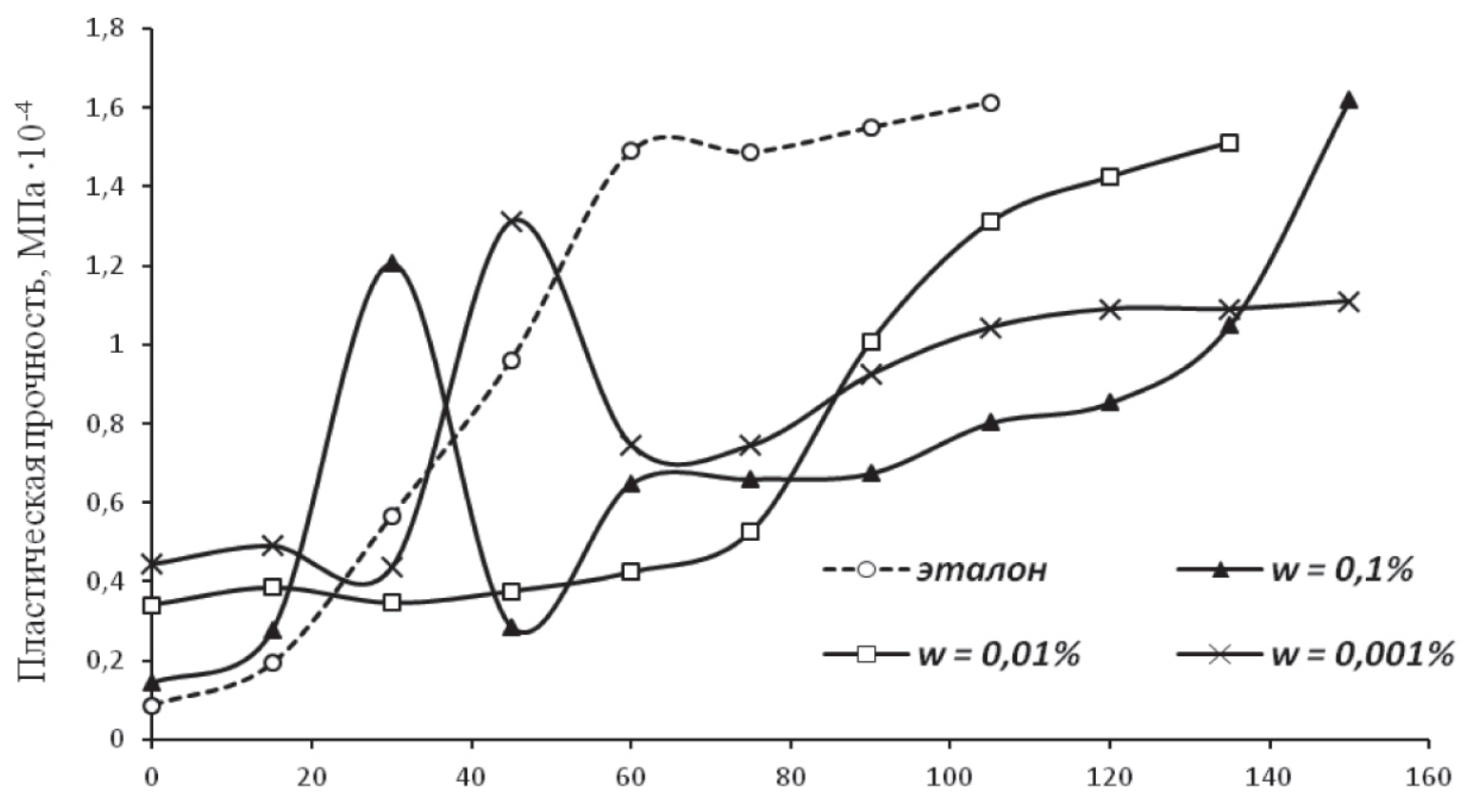

Продолжительность схватывания, мин

Рuc. Кинетика схватывания цементного теста как изменение пластической прочности во времени в зависимости от концентрации (w) КНД.

Далее наблюдается такое же резкое падение значений пластической прочности с последующим ее медленным приростом. Такой характер кинетики схватывания может быть обусловлен процессами кристаллизации метастабильных гидроалюминатов кальция и соответствующим быстрым формированием первичной пространственной коагуляционно-кристаллизационной структуры, эти данные согласуются с работами [18-21]. Последующее образование первичных гидросиликатов кальция вероятно обусловливает быстрое ее разрушение. Данные процессы могут способствовать повышению дефектности структуры цементного камня и оказать негативное влияние на формирование его конструкционного потенциала.

При дозировке КНД 0,01\% от массы цемента значение $\boldsymbol{P}_{m}=1,5 \cdot 10^{-4} \mathrm{MПа,} \mathrm{соответствующее} \mathrm{началу} \mathrm{схватывания,} \mathrm{достигается}$ через 160 мин после затворения цемента водой, т.е. позже стандартных сроков начала схватывания (60-90 мин). При этом рост значений пластической прочности начинается не ранее, чем через 80 мин после 
затворения цемента водой. Таким образом, применение КНД в данной дозировке позволяет увеличить продолжительность периода схватывания. В результате обеспечивается стабильность реологических характеристик модифицированной цементной системы в период времени, в 2 раза более продолжительный, чем для немодифицированной.

\section{Влияние КНД на прочность иелентного камня}

Доказана эффективность использовании КНД в отношении повышения прочности цементного камня. Во-первых, установлено ускорение набора прочности (см. табл.): применение комплексной добавки при всех использованных дозировках позволяет обеспечить до 40\% прочности цементного камня от значений, достигаемых к 28 сут, в течение первых суток. В наномодифицированных системах обеспечивается повышение прочности до 27-28 МПа в первые сутки твердения, до 30-35 МПа - в третьи. У эталонной бездобавочной системы величина прочности составляет 6,5 МПа в возрасте 1 сутки и $20 \mathrm{MПа}-3$ суток. В то же время отмечается повышение предельных значений прочности до 70-77 МПа против $~ 50$ МПа у эталонной бездобавочной системы. Наиболее высокие прочностные показатели отмечаются для варианта дозировки добавки $0,01 \%$ от массы цемента. Такое различие объясняется модифицирующим влиянием добавки на дисперсный и морфологический состав новообразований цементного камня, которые приобретают нанодисперсное и скрытокристаллическое состояние. Именно это и предопределяет более высокое сопротивление модифицированной структуры разрушению.

\section{Заключение}

Доказана эффективность нанотехнологического решения применения специально выращенных наноразмерных частиц для управления реологическими и конструкционными свойствами цементного камня. Эффекты управления структурообразованием связаны [22] с проявлением частицами роли зародышей структурообразования, подложки для кристаллизации, центров зонирования новообразований. Во всех этих случаях существенным моментом является понижение энергетического порога активации процессов синтеза систем твердения и ускорение 
твердения; другим важным моментом оказывается пространственно-геометрическая модификация структуры, заключающаяся, как отмечалось, в ее зонировании и соответствующем влиянии на характеристики однородности-неоднородности материала

Экспериментально доказано, что использование синтезированных авторами комплексных наномодификаторов на основе наночастиц $\mathrm{SiO}_{2}$ и высокоэффективных суперпластификаторов на основе поликарбоксилатных эфиров обеспечивает снижение вязкости цементного теста в $1,3-1,5$ раза. Одновременно использование КНД в оптимизированной дозировке обеспечивает стабильность реологических характеристик модифицированной цементной системы в период времени, в 2 раза более продолжительный, чем немодифицированной.

Введение в цементно-водную систему КНД на основе наночастиц $\mathrm{SiO}_{2}$, родственных по кристаллохимическому строению минералам новообразований цементного камня, определяет эфрфективность наномодифицирования по прочности. При введении КНД цементный камень в 4,5 раза быстрее упрочняется в ранние сроки структурообразования и становиться в 1,5-1,6 раза более прочным при завершении процесса твердения.

Таким образом, применение комплексной наномодифицирующей добавки в оптимизированной дозировке 0,01\% от массы цемента создает условия получения бетонных смесей высокой подвижности, которая стабильно сохраняется в период не менее 3 часов. Важно подчеркнуть, что ускоряется формирование конструкционного потенциала бетонов в начальный период (до 3 сут), что является основанием для сокращения в целом сроков твердения и отказа от тепловой обработки твердеющей цементной системы. Это принципиально важно в арктических условиях возведения сооружений монолитным способом, когда существует необходимость повышения удобоукладываемости бетонных смесей, транспортировки их на дальние расстояния, сокращения сроков набора марочной прочности. 


\section{УВАЖАЕМЫЕ КОЛЛЕГИ! \\ ПРИ ИСПОЛЬЗОВАНИИ МАТЕРИАЛА ДАННОЙ СТАТЬИ \\ ПРОСИМ ДЕЛАТЬ БИБЛИОГРАФИЧЕСКУЮ ССЫЛКУ НА НЕЁ:}

Чернышов Е.М., Славчева Г.С., Арталонова О.В. Управление реологическими и конструкционными свойствами цементного камня при наномодифицировании // Нанотехнологии в строительстве. - 2016. - Том 8, № 6. - С. 87-101. DOI: dx.doi.org/10.15828/2075-8545-2016-8-6-87-101.

\section{DeAR COLleagues! \\ THE REFERENCE TO THIS PAPER HAS THE FOLLOWING CITATION FORMAT:}

Chernishov E.M., Slavcheva G.S., Artamonova O.V. Control of rheological and structural properties cement stone at the nanomodification. Nanotehnologii $\mathrm{v}$ stroitel'stve $=$ Nanotechnologies in Construction. 2016, Vol. 8, no. 6, pp. 87-101. DOI: dx.doi.org/10.15828/2075-8545-2016-8-6-87-101. (In Russian).

\section{Библиографический список:}

1. Чернышов E.M., Арталонова О.В., Коротких Д.Н. и др. Применение нанохимии в технологии твердофазных строительных материалов: научно-инженерная проблема, направление и примеры реализации // Строительные материалы. - 2008. № 2. - C. 32-36.

2. Коротких Д.Н., Арталонова О.В., Чернышов E.M. О требованиях к наномодифицирующим добавкам для высокопрочных цементных бетонов // Нанотехнологии в строительстве. - 2009. - Т. 1, № 2. - С. 42-49. - http://www.nanobuild.ru/magazine/ nb/ Nanobuild_1_2009.pdf.

3. $\quad W u$ M., Johannesson B., Geiker M. A review: Self-healing in cementitious materials and engineered cementitious composite as a self-healing material // Construction and Building Materials. - 2012. - № 28. - P. 571-583.

4. Singh L.P., Agarwal S.K., Bhattacharyya S.K. Preparation of silica nanoparticles and its beneficial role in cementitious materials // Nanomaterials, nanotechnology. - 2011. Vol. 1, № 1. - P. 44-51.

5. $\quad$ Raki L., Beaudoin J., Alizadeh R., Makar J. \& Sato T. Cement and Concrete Nanoscience and Nanotechnology // Materials. - 2010. - № 3. - P. 918-942.

6. Арталонова О.В., Сергуткина О.Р., Коротких Д.Н., Чернышов Е.М. Золь-гель синтез наноразмерных частиц $\mathrm{SiO}_{2}$ для модифицирования структуры цементного камня // Нанотехнологии в строительстве. - 2010. - Т. 2, № 1. - С. 97-105. - http://www. nanobuild.ru/magazine/nb/Nanobuild_2_2010.pdf. 
7. Баженов Ю.М. Использование наносистем в строительном материаловедении // Научно-технический журнал Вестник МГСУ. - 2009. - № 3. - С. 10-13.

8. Koizumi K., Umemura Y., Tsuyuki N. Effects of chemical admixtures on the silicate structure of hydrated portland cement // Proceedings of the 12th International Congress on the Chemistry of Cement. - Montreal, 2007. P. 64-71.

9. Lothenbach B., Winnefeld F., Figi R. The influence of superplasticizers on the hydration of Portland cement // Proceedings of the $12^{\text {th }}$ International Congress on the Chemistry of Cement. - Montreal, 2007. - P. 211-233.

10. Plank J., Bassioni G., Dai Z., Keller H., Sachsenhauser B., Zouaoui N. Neues zur wechselwirkung zwischen zementen und polycarboxylat-fliefimitteln // Proceedings der 16 Internationalen Baustofftagung. Weimar, 2006. - Band 1. - P. 579-598.

11. Quercia G., Hüsken G., Brouwers H.J.H. Water demand of amorphous nanosilica and its impact on the workability of cement paste // Cement and Concrete Research. - 2012. № 42. - P. 344-357.

12. Артамонова О.В., Сергуткина О.Р., Останкова И.В., Шведова М.А. Синтез нанодисперсного модификатора на основе $\mathrm{SiO}_{2}$ для цементных композитов // Конденсированные среды и межфазные границы. - 2014. - Т. 16, № 1. - С. 152-162.

13. Арталонова О.В., Кукина О.Б., Солохин М.А. Исследование структуры и свойств цементного камня, модифицированного комплексной нанодобавкой // Деформация и разрушение материалов. - 2014. - № 11. - С. 18-22.

14. Chernyshev E.M., Artamonova O.V., Slavcheva G.S. Concepts and technology base nanomodification of structures of building composites. Part 3: effective nanomodification of systems and structures of cement hardening cement stone (criteria and conditions) // Строительные материалы. - 2015. - № 10. - С. 54-63.

15. Чернышов Е.М., Славчева Г.С., Арталонова О.В. К концептуальным моделям управления сопротивлением разрушению наномодифицированных структур конгломератных строительных композитов // Известия КГАСУ. - 2014. - № 3 (29). - С. 156-161.

16. Батраков В.Г. Модифицированные бетоны. Теория и практика. - М.: Стройиздат, 1998. - $768 \mathrm{c}$.

17. Goddard W.A., Brenner D.W., Lyshewski S.E., Iafrate G.J. Handbook of nanoscience, engineering, and technology. - Boka Raton: CRC Hress, 2003. - 800 p.

18. Пащенко А.А. Теория цемента. - Киев: Будівельник, 1991. - 168 с.

19. Макридин Н.И., Королев Е.В., Максимова И.Н. Структурообразование и конструкционная прочность цементных композитов: монография. - М.: МГСУ, 2013. - 152 с.

20. Stuzman P. Chemistry and structure of hydration products // Cement Research Progress. - 1999. - № 2. - P. 37-69.

21. Bullard J.W., Jennings H.M., Livingston R.A., et.al. Mechanisms of cement hydration // Cement and Concrete Research. - 2011. - № 41. - P. 1208-1223.

22. Чернышов E.M. Нанотехнологические исследования строительных композитов: общие суждения, основные направления и результаты // Нанотехнологии в строительстве. - 2009. - Том 1, №1. - С. 45-59. - http://www.nanobuild.ru/magazine/ nb/ Nanobuild_1_2009.pdf. 